\title{
Assessing Physicians' Performance when Telling the Truth to Patients Diagnosed with Cancer
}

\author{
Farhad Shahi ${ }^{1}(\mathbb{D})$, Seyed Amir Hossein Emami1 ${ }^{1}$, Mandana Shirazi ${ }^{2,3}$, Samira Mokhtari ${ }^{4}(\mathbb{D})$ \\ Minoosh Moghimi ${ }^{5}$ (D) Sepehr Gohari $\left.{ }^{(i D}\right)$ Zahra Abbaspour $\operatorname{Rad}^{7}$ (D), Reza Mansouri ${ }^{15^{*}}$ (iD)
}

1. Dept. of Hematology \& Medical Oncology, Cancer institute, Imam Khomeini Hospital, Tehran University of Medical Sciences, Tehran, Iran

2. Dept. of Clinical Sciences and Education, Södersjukhuset, Karolinska Institutet, Stockholm, Sweden

3. Dept. of Medical Education, Education Development Center, Tehran University of Medical Sciences, Tehran, Iran

4. Dept. of Neonatology, School of Medicine, Mousavi Hospital, Zanjan University of Medical Sciences, Zanjan, Iran

5. Dept. of Hematology \& Medical Oncology, School of Medicine, Vali-e-Asr Hospital, Zanjan University of Medical Sciences, Zanjan, Iran

6. School of Medicine, Zanjan University of Medical Sciences, Zanjan, Iran

7. Dept. of Internal Medicine, Vali-e-Asr Hospital, Faculty of Medicine, Zanjan University of Medical Sciences, Zanjan, Iran

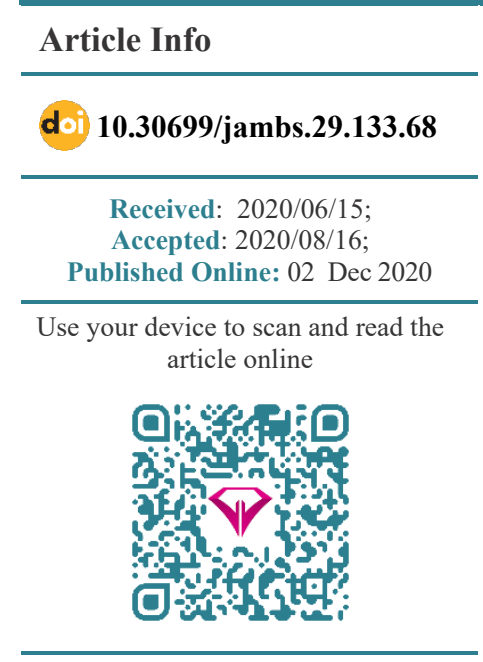

Corresponding Information: Reza Mansouri,

Dept. of Hematology \& Medical Oncology, School of Medicine, Valie-Asr Hospital, Zanjan University of Medical Sciences, Zanjan, Iran

E-Mail:

rezamansouri93@yahoo.com

\begin{abstract}
Background \& Objective: Breaking bad news to patients, especially those diagnosed with cancer, is one of the challengeable issues in the field of medicine. Hence, this study was designed to assess physicians' performance as well as importance of their training on how to deliver bad news to patients diagnosed with cancer.
\end{abstract}

Materials \& Methods: This prospective cross-sectional study assessed physicians' performance in delivering bad health-related news to patients. A total of 12 hematologists and oncologists from Imam Khomeini Hospital and Shariati Hospital in Tehran, Iran were included in the study. A questionnaire including six statements (SPIKES model) was used to evaluate the performance of physicians. The time of breaking the cancer diagnosis news to patients by the physicians and educational records were evaluated with the average score of the physicians related to each statement.

Results: There was no significant difference between the statements and age or gender $(P>0.05)$; but there was a significant correlation between ending the discussion (conversation), summarizing the content, and using the word "cancer" during the conversation $(P<0.05)$. Additionally, there was a significant correlation between the time spent on informing the patient about the cancer diagnosis and concluding the discussion and summarizing the statements $(P<0.05)$.

Conclusion: Guidelines introducing the most harmless methods for delivering bad news with minimal negative effects on the patients' mental health can be helpful for the medical staff. As a result, they can fulfill this critical task with less stress and minimum complications for the patients.

Keywords: Bad news, Cancer, Physician performance

\section{Introduction}

The ability to tell the truth to patients, especially when delivering bad news, is an important factor in a proper doctor-patient relationship. Since the expression or concealment of truth, in addition to moral issues, could also cause legal difficulties, it is important to adopt an appropriate approach to this matter, especially in diseases such as cancer (1).

Over the past thirty years, the trend of changes in social interactions has affected the doctor-patient relationship and led to improved adherence to patient's rights. Accordingly, patients are entitled to know the facts about their illness and doctors, instead of making decisions for patients based on their knowledge and expediency, are required to provide information to the patients and help them make decisions. Thus, developing a proper doctor-patient relationship is crucial for patients' understanding of their health status, their adaptation to the disease and its complications, and their 
commitment to the therapies recommended by the medical team (2-4). Reports have indicated that most cancer patients prefer to be informed about their illness (5). Doctors are also more willing to inform their patients about the cancer diagnosis (6).

It seems that the probability and manner of telling the truth to a cancer patient depends on certain factors, including stage of cancer, cultural conditions of each community, as well as the patient's economic condition, intelligence, and education. The physician's working experience and stage of the disease also affect the physician's opinion (1). Despite the growing awareness of patients and the vital importance of a proper doctorpatient relationship and the way bad news is delivered, most physicians and specialists have not received a structured training in this regard yet (7). In recent years, many efforts have been made to improve the communication skills of medical staff, especially with regard to delivering bad news. Some countries have compiled guidelines in this regard and provided them to physicians and medical staff (8-10). One of such guidelines to present distressing information in an organized manner to patients and families is the SPIKES protocol (setting, patient perception, invitation, knowledge, emotions, summary and strategy) (11). Since there is no structured guideline in this regard in Iran, the current study was designed according to the SPIKES protocol.

\section{Materials and Methods}

\section{Study design, participants, and variables}

A total of 12 hematologists and oncologists from Imam Khomeini and Shariati Hospitals in Tehran, Iran were included in this descriptive cross-sectional study in 2017. Data were collected by a questionnaire for the physicians. The test was designed and conducted in Persian based on SPIKES model; also, the reliability and validity of the questionnaire have been confirmed in other studies $(12,13)$. The questionnaire included six statements: preparing the patient, ending the discussion and summarizing the content, effective communication, using the word 'cancer', preparing the environment, and the patient's right to the information. The relationship between age, gender, the least and most time allotted to deliver the bad news to the patient, the number of patients who have been given bad news in the last three months, the educational records, and the time of delivering cancer diagnosis to the patient by the doctor were all examined with the average score of doctors for each statement. In addition, demographic data including gender, age, patients' records, and physicians' medical education were examined. The study was approved by the Research Ethics Committee of Tehran University of Medical Sciences [code: IR.TUMS.IKHC.REC. 1396. 3411] and informed consent was obtained from all the participants.

\section{Data Analysis}

Quantitative data were expressed as mean and standard deviation and qualitative data were expressed as frequency or relative frequency. Independent sample t-test was used to investigate the relationship between quantitative and qualitative variables with two specific values. One-way ANOVA was employed to investigate the relationship between the quantitative and qualitative variables with more than two values. Linear regression was used to examine the relationship between the quantitative variables.

\section{Results}

\section{Demographic Data}

Out of 12 physicians (faculty members) who participated in this study, 10 were male $(83.3 \%)$ and 2 were female $(16.7 \%)$. The average age of the physicians was $51.08 \pm 6.73$ years old (males: $52.60 \pm 1.75$ vs. females: $43.50 \pm 6.50$ ). Statistically, there was no significant difference between the age of the male and female participants $(P=0.17)$.

\section{Patients' Visit Records Data}

According to the data, $2(16.6 \%), 3(25 \%)$, and 7 $(58.3 \%)$ physicians had informed less than 5,5 to 10 , and more than 10 patients of their cancer diagnosis in the past three months, respectively. The average for least and most time allotted by the physicians to report the bad news was $12.50 \pm 7.53$ and $30.83 \pm 13.79$ minutes, respectively.

\section{Educational Records of Physicians}

Six physicians (50.0\%) had no educational background in medical ethics. Meanwhile, three physicians $(25.0 \%)$ had completed the medical ethics course as a part of their curriculum and 3 physicians $(25.0 \%)$ had completed it as extended education.

\section{Analysis of Study Results \\ Relationship Between Gender and Average Score of Physicians for Each Statement}

According to Table 1, there was no significant relationship between the gender of physicians and the score given by physicians for each statement $(P>0.05)$. Since there were only two female physicians in the present study, these results could not be generalized.

\section{Relationship Between Age and Average Score of Physicians for Each Statement}

The results of the linear regression showed no significant relationship between the mean score of physicians per statement and age of the physicians $(P>0.05)$ (Table 1$)$. 
Relationship Between the Time Allotted to Deliver the Bad News to the Patients and the Average Score of Physicians for Each Statement

Except for ending the discussion and summarizing as well as using the word 'cancer' when breaking the bad news to the patient, the results of linear regression represented no significant relationship between the least and most time allotted to deliver the bad news to the patients and any other statements $(P>0.05)$ (Table 1).

Relationship Between The Number of Patients Who Have Been Given Bad News in the Last Three Months and the Average Score of Physicians in Relation to Each Statement

The results of the one-way ANOVA demonstrated no significant relationship between any of the statements and the number of patients who were given bad news in the past three months $(P>0.05)$ (Table 1).

Relationship Between Educational Background and the Average Score of Physicians for Each Statement

The relationship between educational background and the average score given to each statement was assessed by one-way ANOVA test. A significant relationship was found between having medical ethics training and the average score of the physician in relation to preparing the patient $(P=0.013)$ and ending the discussion and summarizing $(P=0.013)$ statements. Additionally, the results of the data analysis showed a significant relationship between having previous training in delivering bad news and the average score of physicians in relation to preparing the patient ( $P=0.031)$, ending the discussion and summarizing $(P=0.00)$, and the patient's right to be informed of their cancer diagnosis $(P=0.02)$ statements (Table 1$)$.

Relationship Between the Time of Delivering the Cancer Diagnosis to the Patient by the Physician and the Average Score of Physicians in Relation to Each Statement

The one-way ANOVA test showed a significant relationship between the time of delivering the news to the patient and ending the discussion and summarizing $(P=0.049)$, patient's right to know about their cancer diagnosis $(P=0.036)$, and effective communication $(P=0.037)$ statements $($ Table 1$)$.

Table 1. The relationship between different factors associated with delivering cancer diagnosis to the patient by the physician and the average score of physicians in relation to each statement

\begin{tabular}{|c|c|c|c|c|c|c|c|}
\hline Variable & & $\begin{array}{l}\text { Preparing } \\
\text { the patient }\end{array}$ & $\begin{array}{l}\text { Ending the } \\
\text { discussion and } \\
\text { summarizing }\end{array}$ & $\begin{array}{c}\text { Effective } \\
\text { communication }\end{array}$ & $\begin{array}{l}\text { Using the } \\
\text { word } \\
\text { 'cancer' }\end{array}$ & $\begin{array}{l}\text { Preparing the } \\
\text { environment }\end{array}$ & $\begin{array}{l}\text { The patient's } \\
\text { right to know } \\
\text { about their } \\
\text { cancer } \\
\text { diagnosis }\end{array}$ \\
\hline \multirow{2}{*}{$\begin{array}{l}\text { Gender } \\
(\text { Mean } \pm \text { SD) }\end{array}$} & Male & $4.00 \pm 0.166$ & $4.48 \pm 0.146$ & $4.13 \pm 0.200$ & $2.50 \pm 0.182$ & $3.80 \pm 0.239$ & $3.75 \pm 0.153$ \\
\hline & Female & $4.62 \pm 0.125$ & $4.70 \pm 0.100$ & $4.665 \pm 0.333$ & $2.75 \pm 0.250$ & $4.16 \pm 0.166$ & $3.25 \pm 0.250$ \\
\hline$P$ value & & 0.140 & 0.535 & 0.291 & 0.576 & 0.527 & 0.203 \\
\hline \multirow{2}{*}{$\begin{array}{l}\text { Age } \\
(\text { Mean } \pm \text { SD) }\end{array}$} & $\begin{array}{l}\text { Less than } \\
50\end{array}$ & $4.20 \pm 0.284$ & $4.63 \pm 0.158$ & $4.55 \pm 0.164$ & $2.66 \pm 0.247$ & $4.16 \pm 0.319$ & $3.75 \pm 0.214$ \\
\hline & $\begin{array}{l}\text { More } \\
\text { than } 50\end{array}$ & $4.00 \pm 0.144$ & $4.40 \pm 0.193$ & $3.68 \pm 0.267$ & $2.41 \pm 0.200$ & $3.55 \pm 0.204$ & $3.58 \pm 0.200$ \\
\hline$P$ value & & 0.871 & 0.929 & 0.581 & 0.820 & 0.515 & 0.944 \\
\hline \multirow{3}{*}{$\begin{array}{l}\text { Least amount of time } \\
\text { (Mean } \pm \text { SD) }\end{array}$} & $\begin{array}{l}\text { Less than } \\
5 \mathrm{~min}\end{array}$ & $3.39 \pm 0.56$ & $4.30 \pm 0.35$ & $4.80 \pm 0.37$ & $2.12 \pm 0.18$ & $3.17 \pm 0.34$ & $3.50 \pm 0.71$ \\
\hline & $\begin{array}{l}5 \text { to } 10 \\
\min \end{array}$ & $3.87 \pm 0.12$ & $4.73 \pm 0.47$ & $3.33 \pm 0.16$ & $2.25 \pm 0.89$ & $3.15 \pm 0.91$ & $3.25 \pm 0.38$ \\
\hline & $\begin{array}{c}\text { More } \\
\text { than } 10 \\
\min \end{array}$ & $4.29 \pm 0.25$ & $4.73 \pm 0.71$ & $3.70 \pm 0.84$ & $2.50 \pm 0.91$ & $4.16 \pm 0.33$ & $3.91 \pm 0.81$ \\
\hline$P$ value & & 0.084 & 0.048 & 0.087 & 0.012 & 0.180 & 0.705 \\
\hline \multirow{2}{*}{$\begin{array}{l}\text { Most amount of time } \\
(\text { Mean } \pm \text { SD) }\end{array}$} & $\begin{array}{l}10 \text { to } 20 \\
\min \end{array}$ & $3.93 \pm 0.25$ & $4.30 \pm 0.17$ & $4.08 \pm 0.15$ & $2.15 \pm 0.12$ & $3.75 \pm 0.15$ & $3.50 \pm 0.20$ \\
\hline & $\begin{array}{c}\text { More } \\
\text { than } 20 \\
\min \end{array}$ & $4.18 \pm 0.61$ & $4.63 \pm 0.19$ & $4.29 \pm 0.26$ & $2.75 \pm 0.18$ & $3.91 \pm 0.30$ & $3.75 \pm 0.18$ \\
\hline$P$ value & & 0.258 & 0.043 & 0.222 & 0.052 & 0.327 & 0.704 \\
\hline $\begin{array}{l}\text { Number of patients in } \\
\text { the last three months }\end{array}$ & $\begin{array}{l}\text { Less than } \\
5\end{array}$ & $4.00 \pm 0.500$ & $4.50 \pm 0.100$ & $4.16 \pm 0.166$ & $2.50 \pm 0.250$ & $3.83 \pm 0.166$ & $4.16 \pm 0.166$ \\
\hline
\end{tabular}




\begin{tabular}{|c|c|c|c|c|c|c|c|}
\hline Variable & & $\begin{array}{l}\text { Preparing } \\
\text { the patient }\end{array}$ & $\begin{array}{l}\text { Ending the } \\
\text { discussion and } \\
\text { summarizing }\end{array}$ & $\begin{array}{c}\text { Effective } \\
\text { communication }\end{array}$ & $\begin{array}{l}\text { Using the } \\
\text { word } \\
\text { 'cancer' }\end{array}$ & $\begin{array}{l}\text { Preparing the } \\
\text { environment }\end{array}$ & $\begin{array}{l}\text { The patient's } \\
\text { right to know } \\
\text { about their } \\
\text { cancer } \\
\text { diagnosis }\end{array}$ \\
\hline \multirow[t]{2}{*}{$(\mathrm{Mean} \pm \mathrm{SD})$} & 5 to 10 & $4.58 \pm 0.220$ & $4.86 \pm 0.133$ & $4.44 \pm 0.111$ & $3.16 \pm 0.166$ & $4.55 \pm 0.444$ & $3.58 \pm 0.200$ \\
\hline & $\begin{array}{l}\text { More } \\
\text { than } 10\end{array}$ & $3.95 \pm 0.218$ & $4.30 \pm 0.198$ & $4.16 \pm 0.362$ & $2.33 \pm 0.210$ & $3.56 \pm 0.267$ & $2.50 \pm 0.250$ \\
\hline$P$ value & & 0.384 & 0.289 & 0.930 & 0.122 & 0.262 & 0.133 \\
\hline \multirow{3}{*}{$\begin{array}{l}\text { Training in } \\
\text { ethics } \\
(\text { Mean } \pm \text { SD) }\end{array}$} & Yes & $4.39 \pm 0.162$ & $4.89 \pm 0.068$ & $4.42 \pm 0.119$ & $2.92 \pm 0.130$ & $4.03 \pm 0.214$ & $3.71 \pm 0.214$ \\
\hline & No & $3.21 \pm 0.183$ & $3.67 \pm 0.101$ & $3.93 \pm 0.385$ & $2.34 \pm 0.135$ & $3.57 \pm 0.235$ & $3.60 \pm 0.187$ \\
\hline & & 0.013 & 0.013 & 0.079 & 0.541 & 0.899 & 0.260 \\
\hline \multirow{2}{*}{$\begin{array}{l}\text { Training in de } \\
\text { bad news } \\
(\text { Mean } \pm \text { SD) }\end{array}$} & Yes & $4.50 \pm 0.144$ & $4.83 \pm 0.080$ & $4.40 \pm 0.113$ & $2.85 \pm 0.129$ & $4.03 \pm 0.227$ & $3.83 \pm 0.210$ \\
\hline & No & $3.70 \pm 0.150$ & $4.20 \pm 0.146$ & $3.94 \pm 0.315$ & $2.53 \pm 0.083$ & $3.68 \pm 0.200$ & $3.50 \pm 0.182$ \\
\hline$P$ value & & 0.000 & 0.012 & 0.128 & 0.510 & 0.112 & 0.017 \\
\hline $\begin{array}{l}\text { Time of delivering the } \\
\text { bad news }\end{array}$ & $P$ value & 0.441 & 0.049 & 0.037 & 0.742 & 0.036 & 0.434 \\
\hline
\end{tabular}

\section{Discussion}

The present study showed that, despite having work experience, training experience for delivering bad news, is important. Almost all the physicians (11 out of 12 physicians) expressed the need for a structured guideline on how to deliver bad news to patients. This result is consistent with the study conducted by Biazar et al. in which $83 \%$ of participants expressed the need for educational courses for breaking bad news (14). Some countries have already compiled guidelines in this regard and provided them to physicians and medical staff (8-10).

In this study, no significant relationship was observed between different statements and age and gender. Due to the small number of male and female physicians, it is not possible to rely on the statistical tests regarding the age difference between the male and female physicians. Shah Shahsanai et al. reported no significant association between physicians' gender and their opinion on telling the truth to patients with cancer in early stages, while there was a significant relationship between male and female physicians' views on telling the truth to the patients with advanced cancer; $54 \%$ of females and only $10 \%$ of males agreed to tell the truth to the patients with cancer in advanced stages (1).

The results of the present study showed that the physicians who passed medical ethic courses had relatively higher scores. These results are consistent with the findings of two clinical trials carried out by Baghdari et al. and Managheb et al. $(15,16)$.

Additionally, the results of this study showed a significant relationship between the time of informing the patients about their cancer diagnosis and summarizing and ending the discussion $(P=0.049)$, the patients' right to know about their illness $(P=0.036)$, and effective communication $(P=0.037)$ statements. Physicians who believed in delivering bad news to the patient as soon as they were diagnosed with cancer scored higher on these statements. It seems that the physician's attitude towards telling the truth to the patient is closely related to their performance in delivering bad news. Therefore, education and training in subjects like understanding patients' rights and also medical ethics courses can play a major role in improving the physicians' performance when delivering bad news.

Although in this study providing a calm, private, and confidential environment as well as allotting more time to delivering the bad news meant higher scores, physicians could not dedicate more time to delivering bad news and preparing patients, so that they can come into terms with the news more easily since proper and specific physical space and facilities are lacking in the hospitals.

\section{Conclusion}

Additionally, other factors that may contribute to poor performance in delivering bad news were the use of the word 'cancer' and not introducing the patient to psychological counseling. Therefore, more research on how physicians tend to deliver bad news is necessary in order to explain and discover its various aspects based on the experiences of patients, their families, and medical staff. To sum up, guidelines which are introducing the most harmless methods to delivering bad news with minimal negative effects on patients' 
mental health can be helpful for the medical staff, so that they can fulfill this critical task with less stress and minimum complications for patients.

\section{Data availability:}

The raw data supporting the findings of this study are available in case of any request.

\section{Acknowledgments}

To use and publish the scientific data obtained by the questionnaire, a written consent form was obtained from the author of the article who designed the form.

We thank all the physicians who participated in and contributed to the study.

\section{Ethical considerations}

Ethical issues (Including plagiarism, informed consent, misconduct, data fabrication and/or falsification, double publication and/or submission, redundancy, etc.) have been completely observed by the authors.

\section{Funding and support}

This research resulted from an independent research without receiving any financial support.

\section{Conflict of Interest}

Authors declared no conflict of interest.

\section{References}

1. Shahsanai A, Zamani A, Kivan S, Hematti S, Mokarian F. Iranian physicians and patients attitude toward truth telling of cancer. J Med Ethics. 2016;4(13):145-65.

2. Ong LM, De Haes JC, Hoos AM, Lammes FB. Doctor-patient communication: a review of the literature. Soc Sci Med. 1995;40(7):903-18. [DOI:10.1016/0277-9536(94)00155-M]

3. Schwarz B, Benson JJ. Care Pathways for the Dying Patients: Physician Perspective. J Hous Elderly. 2018;32(3-4):431-61 [DOI:10.1080/02763893.2018.1505463]

4. Dhage AS, Wilkinson AR. Breaking bad news of cancer diagnosis-the patient's perspective. IJRMS. 2017;5(4):1617-21. [DOI:10.18203/2320-6012.ijrms20171275]

5. Jenkins V, Fallowfield L, Saul J. Information needs of patients with cancer: results from a large study in UK cancer centres. $\mathrm{Br} \mathrm{J}$ Cancer. 2001;84(1):48-51.

[DOI:10.1054/bjoc.2000.1573]

6. Seo M, Tamura K, Shijo H, Morioka E, Ikegame C, Hirasako K. Telling the diagnosis to cancer patients in Japan: attitude and perception of patients, physicians and nurses. Palliat Med. 2000;14(2):105-10. [DOI:10.1191/026921600676888353]

7. Gorniewicz J, Floyd M, Krishnan K, Bishop TW, Tudiver F, Lang F. Breaking bad news to patients with cancer: a randomized control trial of a brief communication skills training module incorporating the stories and preferences of actual patients. Patient Educ Couns. 2017;100(4):65566. [DOI:10.1016/j.pec.2016.11.008]

8. Street Jr RL, Mazor KM, Arora NK. Assessing patient-centered communication in cancer care: measures for surveillance of communication outcomes. J Oncol Pract. 2016;12(12):1198. [DOI:10.1200/JOP.2016.013334]

9. Karnieli-Miller O, Palombo M, Meitar D. See, reflect, learn more: qualitative analysis of breaking bad news reflective narratives. Med Educ. 2018;52(5):497-512. [DOI:10.1111/medu.13582]

10. Girgis A, Sanson-Fisher RW. Breaking bad news: consensus guidelines for medical practitioners. J Clin Oncol. 1995;13(9):2449-56. [DOI:10.1200/JCO.1995.13.9.2449]

11. Baile WF, Buckman R, Lenzi R, Glober G, Beale EA, Kudelka AP. SPIKES-a six-step protocol for delivering bad news: application to the patient with cancer. Oncologist. 2000;5(4):302-11. [DOI:10.1634/theoncologist.5-4-302]

12. Borjalilu S, Karbakhsh M, Mirsharifi R, Davoodzadeh K, Aghili M, Kaviani A. Measuring Attitude and Practice of Physician toward Breaking Bad News to the Breast Cancer Patients: Development and Validation of a Questionnaire. Arch Breast Cancer. 2016;10:41-9.

13. Farber NJ, Urban SY, Collier VU, et al. The good news about giving bad news to patients. J Gen Intern Med. 2002;17(12):914-22. [DOI:10.1046/j.1525-1497.2002.20420.x]

14. Biazar G, Delpasand K, Farzi F, Sedighinejad A, Mirmansouri A, Atrkarroushan Z. Breaking Bad News: A Valid Concern among Clinicians. Iran J Psychiatry. [DOI:10.18502/ijps.v14i3.1321]

15. Baghdari N, Torkmannejad Sabzevari M, Karimi Moonaghi H, Rad M, Amiri M. The effect of educational approaches on knowledge and attitude of midwifery students in breaking bad news to patients. J Med Educ Dev. 2016;9(22):1220. 
16. Managheb S, Mosalanejad N. The impact of role play and group discussion on the knowledge and attitude of interns of Jahrom Medical School about breaking bad news, 2009. J Jahrom Univ Med Sci. 2011;9.

\section{How to Cite This Article:}

Shahi F, Emami A H, Shirazi M, Mokhtari S, Moghimi M, Gohari S, et al . Assessing Physicians' Performance when Telling the Truth to Patients Diagnosed with Cancer. J Adv Med Biomed Res. 2021; 29 (133) :68-73

Download citation:

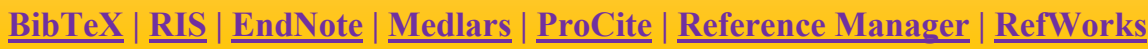

Send citation to:

Mendeley (2) Zotero (i) RefWorks RefWorks 